\title{
Retrato del individuo posmoderno en el cine de Yorgos Lanthimos
}

\author{
The post-modern individual in Yorgos Lanthimos' cinema
}

\author{
Mikel Peña Sarrionandia \\ Universidad del País Vasco | Barrio Sarriena, s/n, 48940 Vizcaya| España | \\ http://orcid.org/0000-0002-7663-7708| mpena018@ikasle.ehu.eus
}

Fechas | Recepción: 11/09/2021 | Aceptación: 06/12/2021

\section{Resumen}

En el año 2018 Yorgos Lanthimos recibió diez nominaciones a los premios Oscar gracias a su película The Favourite. Además de eso, el autor también se ha convertido en un habitual en el Festival de Cannes. Estos premios suponen un gran reconocimiento, y más aún cuando hablamos de un director alternativo que proviene de una Grecia sumida en la más profunda crisis económica. El presente trabajo analiza las películas de Lanthimos y reflexiona sobre el retrato que hace el autor del individuo posmoderno. Identifica los rasgos y características comunes que se repiten a lo largo de su filmografía y a partir de su análisis invita a meditar sobre el individuo y el sistema capitalista actual. Entre los resultados, se destaca que en la sociedad contemporánea posmoderna el individuo ha sufrido un fuerte proceso de alienación. La identidad propia ha sido negada y las relaciones románticas han sido convertidas en una fuente de placer inmediata y desechable. El sexo se ha convertido en una mercancía. El lenguaje ha mostrado su inutilidad a la hora de crear lazos afectivos entre personas y de dar sentido a la realidad y se ha convertido en una herramienta con la que los poderosos mantienen a sus súbditos bajo control. Como consecuencia, los individuos no consiguen conectar entre ellos y a falta de un objetivo común se encuentran aislados y solos.

\begin{abstract}
In 2018, Yorgos Lanthimos' film The Favourite received 10 Oscar nominations. The director also became a regular in Cannes. These awards are a great recognition of Lanthimos' success, and are even more poignant for an alternative filmmaker who started in crisis-hit Greece. This work analyses Lanthimos' films and deliberates about the portrait the author makes of the postmodern individual. It identifies the common characteristics throughout its filmography and from those observations it invites meditation on the current capitalist system. It argues that in contemporary post-modern society individuals have suffered a strong alienating process in which subjectivity has been denied. Romantic relationships have become an immediate and disposable source of pleasure and sex has become a consumable good. Language has shown its inefficiency in creating emotional ties between people and also in its purpose of making sense of reality and it has become a tool for the powerful to keep their subjects under control. As a consequence, individuals are unable to connect with each other and in the absence of a common goal they find themselves completely isolated and alone.
\end{abstract}


Palabras clave: Yorgos Lanthimos, análisis Keywords: Yorgos Lanthimos, film analysis, fílmico, posmodernismo, neoexistencialismo, post-modernism, neo-existentialism, Identity. identidad.

\section{INTRODUCCIÓN: QUÉ ES EL CINE POSMODERNO}

"Lo que se ha roto ya no puede ser pegado. Abandonen toda esperanza de unidad, tanto futura como pasada, ustedes, los que ingresan al mundo de la modernidad fluida", escribe Zygmunt Bauman en su famoso libro Modernidad líquida (2003, p. 27). Según el sociólogo, la sociedad actual está rota: los valores y los principios que regían la sociedad en el pasado han desaparecido y un relativismo generalizado ha ocupado su lugar. Nos encontramos ante lo que Bauman denomina sociedad líquida, pero que muchos otros autores han denominado posmoderna:

La posmodernidad es un estilo de pensamiento que desconfía de las nociones clásicas de verdad, razón, identidad y objetividad, de la idea de progreso universal o de emancipación, de las estructuras aisladas, de los grandes relatos o de los sistemas definitivos de explicación. Contra esas normas iluministas, considera el mundo como contingente, inexplicado, diverso, inestable, indeterminado, un conjunto de culturas desunidas o de interpretaciones que engendra un grado de escepticismo sobre la objetividad de la verdad, la historia y las normas, lo dado de las naturalezas y la coherencia de las identidades. (Eagleton, 1997, p. 11)

Al tiempo que la sociedad ha cambiado, el cine también ha evolucionado junto a ella. Así, en los últimos años ha surgido una corriente en la que varios autores de diferentes nacionalidades reflexionan sobre la condición humana y el sentido de la existencia, en lo que Gérard Imbert en su libro Crisis de valores en el cine posmoderno denomina cine neoexistencialista (Imbert, 2019).

Ahora bien, ¿̇n qué se diferencia el cine posmoderno neoexistencialista del cine clásico? Para empezar, en el cine clásico la narración era una construcción coherente. Los recursos técnicos siempre estaban al servicio de la narración y los autores intentaban contar la historia de la forma más clara y entendible posible. Los personajes tenían valores bien definidos e iban superando obstáculos hasta llegar a una conclusión lógica final (Bordwell, 1996). Pero, como hemos dicho antes, la sociedad está cambiando y los valores absolutos y las certezas están desapareciendo; la línea entre el bien y el mal se está volviendo difusa. En consecuencia, el cine posmoderno rompe con el pensamiento binario del cine clásico y abraza la complejidad del ser humano. Dejando atrás las certezas, se embarca en un ejercicio de exploración y reflexión.

No solo aparecen nuevos temas en el cine posmoderno, sino que además hay un cambio radical en la forma de representación que adquieren dichos temas. La causalidad y la continuidad pierden importancia y aparecen relatos que inquietan y cuestionan. La observación se vuelve esencial $y$, en consecuencia, muchas películas se asemejan al cine documental. Así describe Horacio Muñoz la narrativa del cine posmoderno en su tesis Posnarrativo: el cine más allá de la narración: 
El cine posnarrativo [...] nos descubre que más allá de las historias existen espacios de sentido, de visualidad, de temporalidad y de gestualidad que solo aparecen en la imagen cuando el cine se libera de las constricciones narrativas, primando el espacio, el tiempo y el cuerpo. El cine más allá de la narración nos muestra realidades, sensaciones y emociones que están más allá de lo textual y lo conceptual; un cine donde la verdad, la emoción y la profundidad están en la imagen y no en la narrativa. (Muñoz, 2015, p. 14)

Sería difícil, si no imposible, definir y clasificar todas las características del cine posmoderno, ya que estas pueden variar de un autor a otro. El objetivo de este trabajo es analizar el cine del autor griego Yorgos Lanthimos, con la intención de exponer la representación que el autor hace del individuo posmoderno. Para ello, se analizarán en profundidad las películas del director y se identificarán las principales características con las que dibuja las sociedades y los personajes en su cine. A partir de ese análisis, se expondrá una serie de elementos que caracterizan al individuo contemporáneo.

La metodología utilizada para analizar las películas del director se basará en el análisis fílmico textual. Además, se utilizarán textos de disciplinas como la filosofía o la sociología para enriquecer y completar esta investigación de naturaleza cualitativa.

Lanthimos es un director que experimenta con generar reacciones en el espectador. En sus películas ha creado una extensa red de metáforas y ha planteado reflexiones sobre la forma en la que nos relacionamos en la sociedad contemporánea. Se trata de un director relativamente joven cuya fama ha ido en aumento en los últimos años. Consiguió el prestigioso premio Un Certain Regard en Cannes en 2009 y a partir de ahí su popularidad ha ido creciendo rápidamente hasta el punto de que su última película, The Favourite (Lanthimos, 2018), recibió diez nominaciones a los premios Oscar. Estos premios suponen un gran reconocimiento, que se pronuncia aún más cuando hablamos de un director alternativo que proviene de una Grecia sumida en la más profunda crisis económica. El éxito de Lanthimos ha sido repentino, y aún no hay muchas investigaciones académicas que estudien su forma de hacer cine. Se hace mención a su obra en algunos trabajos que estudian la Nueva Extraña Ola Griega ${ }^{1}$, pero actualmente tan solo hay un libro publicado que se centre en la obra del director, el escrito Anestesia di solitudini: Il cinema di Yorgos Lanthimos de Roberto Lasagna y Benedetta Pallavidino (Lasagna y Pallavidino, 2019). Aparte de ese libro, los estudios académicos que traten el cine del director en profundidad son escasos, por lo que subrayamos la importancia de realizar esta investigación.

El primer elemento que analizaremos será la negación de la identidad, donde observaremos cómo en el cine de Yorgos Lanthimos tanto el sujeto posmoderno como los espacios en los que habita han sido privados de su identidad. En el siguiente apartado hablaremos sobre los dos principales tipos de relaciones amorosas que se pueden encontrar en la sociedad actual: el amor romántico y el amor líquido. Después observaremos cómo el lenguaje ha fracasado en su función de conectar a los seres humanos y dar sentido al mundo, y a continuación examinaremos el aislamiento entre individuos que ha acarreado dicho fracaso. Para terminar, plantearemos un apartado de conclusiones donde resumiremos lo analizado en el trabajo.

\footnotetext{
${ }^{1}$ Como, por ejemplo, The Queer Greek Weird Wave: Ethics, Politics and the Crisis of Meaning, de Marios Psaras (Psaras, 2016) o Greek Weird Wave: a cinema of biopolitics, de Dimitris Papanikolaou (Papanikolaou, 2020).
} 


\section{NEGACIÓN DE LA IDENTIDAD}

Una de las principales características de los personajes de Lanthimos es su falta de identidad, que se hace evidente en la mayoría de las películas. Un buen ejemplo de ello se encuentra en Alps (Lanthimos, 2012), donde los personajes forman un grupo -llamado Alpes- que ofrece sus servicios para sustituir a personas que han fallecido. Es decir; si una familia pierde a su hija en un accidente, por ejemplo, puede contratar a los Alpes para que, un par de veces por semana, uno de sus miembros vaya a casa de la familia y actúe como si fuera la hija fallecida. La cinta no trata sobre el dolor que causa la pérdida de un ser querido, sino que explora la necesidad del ser humano de tener una identidad, de ser alguien.

Pero empecemos por el principio. ¿Qué es la identidad? Navarrete-Cazales nos da la siguiente definición:

La identidad es una categoría general que posibilita que tengamos un lugar de adscripción (histórico-temporal) frente a los demás a distinguirnos de los otros (sujetos, instituciones, grupos, familias, comunidades, movimientos sociales, naciones), y decir qué es lo que somos y lo que no somos. (Navarrete-Cazales, 2015, p. 468)

La identidad, por tanto, nos dice qué es lo que somos y lo que no somos. Y, en ese sentido, el ser humano necesita tener una identidad para ser alguien. La identidad nos da la oportunidad de ser algo o alguien, un individuo propio y diferente de los demás.

Resaltamos aquí la importancia de ese "los demás", pues a pesar de que en la filosofía clásica se entendiera la identidad como una relación que cada uno mantenía consigo mismo, en la actualidad se argumenta que la identidad se forma mediante los comportamientos, actitudes y gestos que el individuo realiza frente a los demás. Valerio D’Angelo, siguiendo las enseñanzas de Erving Goffman, cita a Simone de Beauvoir, "cuando describe cómo las mujeres se vuelven mujeres, comportándose como mujeres, esto es representando un rol" (2016, p. 394). JeanPaul Sartre también razonaba en la misma dirección cuando escribía que "no basta con nacer burgués, hay que vivir la vida como un burgués. (Bauman, 2003, p. 37)

Hoy en día, por lo tanto, se cree que la identidad se forma actuando, representando un papel. La mujer se hace mujer actuando como una mujer; el profesor, actuando como profesor; el padre, actuando como padre. De esta forma, el término persona (entendido como individuo con una identidad propia) vuelve al significado etimológico que tenía en la antigüedad, puesto que este termino se utilizaba para nombrar las máscaras que los actores utilizaban en la tragedia griega:

Diversos autores coinciden en aceptar su proveniencia del término griego "prosopon", que era la máscara utilizada por los actores del teatro griego en las representaciones. También se reconoce su origen en el término latino "per-sonare", que significaba "sonar a través de". Los estudios etimológicos permiten afirmar que "persona" era la máscara a través de la cual resonaba la voz. (Betancur, 2010, p. 130)

El término persona nació para nombrar las máscaras de los actores. Después pasó a nombrar a los individuos que utilizaban esas máscaras, esto es, los actores, y al final terminó nombrando a todos los individuos de la sociedad. Pero es interesante remarcar que persona viene de máscara o de actor, pues esto es precisamente lo que los filósofos contemporáneos afirman que es la persona: un actor: 
La persona es la máscara o el rol que asumen los individuos en sociedad. Somos actores de nuestra propia vida en la que desempeñamos múltiples papeles sociales; somos padres, profesionales, hijos, esposos, amigos, etc. [...] El hombre es, entonces, un personaje que cumple un rol en el escenario del mundo; [...] Y, en este sentido, el hombre es persona. (Betancur, 2010, p. 130)

La persona es el rol que el individuo asume en la sociedad, es una máscara. $Y$ esa es precisamente la clave para entender por qué la protagonista de Alps, llamada Monte Rosa, se empeña con tanto ahínco en representar los roles de las personas fallecidas. La joven no consigue ser percibida por los demás, no consigue que la sociedad la reconozca como un individuo. Es una persona sin identidad, una persona-que-no-es-persona. $\mathrm{Y}$ es precisamente actuando como si lo fuera, como si fuera la hija o la novia de alguien, aunque sea durante unas horas, como Monte Rosa quiere llegar a convertirse en alguien.

Llama la atención que el nombre de la protagonista de Alps sea precisamente Monte Rosa, pues este es el nombre de uno de los montes que componen la conocida cordillera de los Alpes. La razón de ello es que Monte Rosa es solo el sobrenombre que elige la protagonista de la película, pues su nombre real nunca se da a conocer. Estamos aquí ante otra de las características del cine de Lanthimos: al negar a los personajes de una identidad, también les niega un nombre. Así pasa en Kinetta (Lanthimos, 2005), su primera película, y también en Dogtooth (Lanthimos, 2009).

Al mismo tiempo, la negación del rostro también cumple la misma función: si el individuo se vuelve persona realizando diferentes actuaciones, es innegable que el cuerpo y el rostro cumplen un papel fundamental para que esas actuaciones tengan lugar. "El rostro nos identifica. A las víctimas de un incendio no les basta con salvar su vida: necesitan tener un rostro. Aunque sea el de un muerto" asegura el doctor Ledgard al inicio de la película La piel que habito (Pedro Almodóvar, 2011). El rostro nos identifica, nos da la oportunidad de construirnos una identidad, de ser alguien. En Alps el director niega los rostros de los personajes y los coloca constantemente de espaldas a la cámara, desenfocados o lejos de ella $[1,2]$.

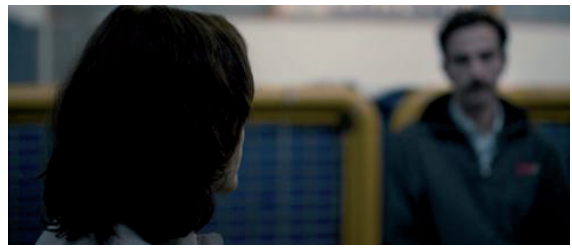

Figura 1. Negación del rostro

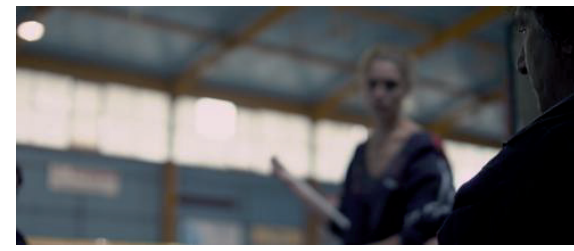

Figura 2. Negación del rostro

Lo mismo sucede en Kinetta. En la escena que presenta al personaje principal, por ejemplo, esta aparece desenfocada, oscura y casi fuera del fotograma [3]. En los siguientes planos el director muestra los movimientos de su cuerpo, pero su rostro siempre elude la cámara: primero se ve a la protagonista de lado o de espaldas al espectador, y después el rostro queda oculto detrás de un objeto [4]. 


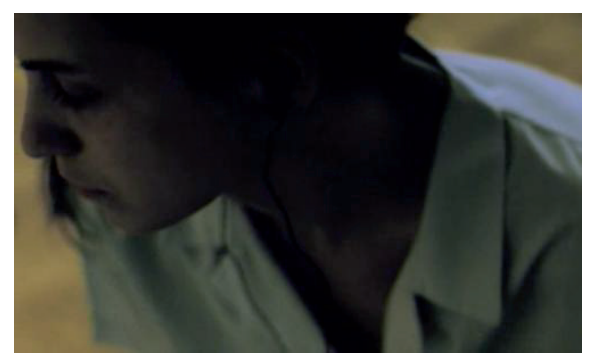

Figura 3. Negación del rostro

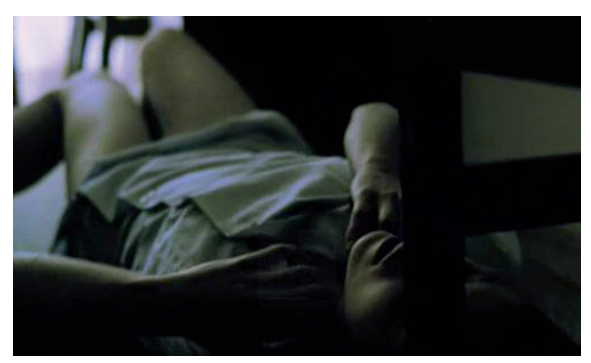

Figura 4. Negación del rostro

Privados de la herramienta del rostro a la hora de construirse una identidad, los personajes de Lanthimos no consiguen que los demás se crean sus conductas, lo cual es un elemento imprescindible para que las actuaciones funcionen: "El "sí mismo" (self), según Mead, emerge como sujeto sólo en la medida en que es capaz de "objetivarse", es decir, de ser reconocido por los demás en cuanto sujeto" (D’Angelo, 2016, p. 390). Es en el reconocimiento de los demás donde reside la clave de la identidad. Cuando el individuo realiza un rol, pide que los demás se crean ese rol: "Se les pide que crean que el sujeto que ven posee en realidad los atributos que aparenta poseer, que la tarea que realiza tendrá las consecuencias que en forma implícita pretende y que, en general, las cosas son como aparentan ser" (Goffman, 1997, p. 29). Pero cuando esto no ocurre, cuando la máscara no es creíble y el resto no se cree el rol que uno está realizando, el individuo fracasa en su construcción de la identidad.

Monte Rosa intenta desesperadamente ser alguien actuando como tal, pero el resto de personas son conscientes de que están ante una recreación en todo momento. No se creen a la joven. $Y$ es por ello que fracasa en su intento de conseguir una identidad.

En The Lobster (Lanthimos, 2015) la negación de identidad se plasma en el despojamiento de los objetos personales que sufren los personajes cuando llegan al hotel donde se sitúa la primera parte de la película. Como hemos dicho antes, la identidad se construye con actuaciones para los que el cuerpo, el rostro y la "fachada", como lo denomina D'Angelo, son esenciales:

La primera regla situacional consiste en la "gestión disciplinada de la propia apariencia o fachada personal", con la finalidad de presentar una identidad creíble a los demás. Del buen uso de los elementos expresivos, o sea del cuidado de la fachada, depende el éxito de la performance. Sin embargo hay contextos, como las cárceles y los hospitales psiquiátricos donde el preso se ve privado de este derecho a la máscara. (D’Angelo, 2016, p. 392)

En The Lobster privan a los huéspedes del hotel de sus objetos personales y de su ropa. Visten a todos de la misma manera, les hacen bailar igual, comer igual $[5,6] . .$. y de esa forma le niegan al individuo la posibilidad de construirse una identidad diferente, de ser alguien diferente, de decidir acerca de su máscara. 


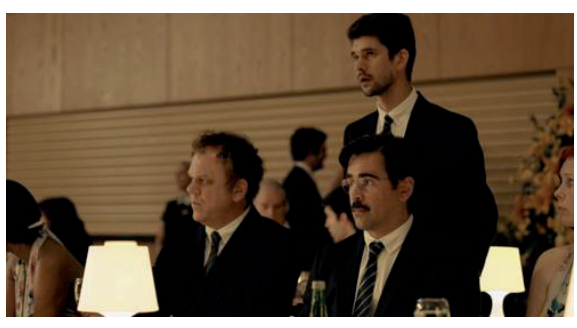

Figura 5. Negación de la fachada

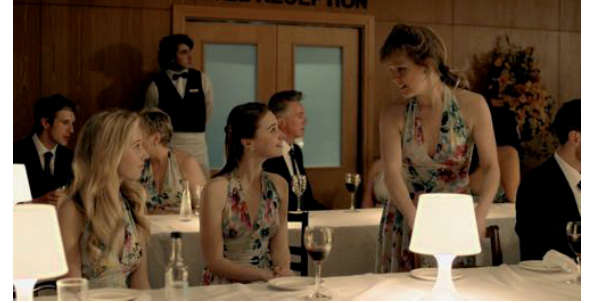

Figura 6. Negación de la fachada

En el resto de películas del director griego también es evidente la falta de identidad de los personajes, por lo que este elemento se convierte en la primera característica que remarcamos del individuo posmoderno: ha sido privado de su identidad. No obstante, cabe destacar que la negación de la identidad no es un elemento exclusivo de las personas; también se da en los lugares.

\subsection{No-lugares}

De la misma manera en la que Lanthimos niega la identidad de los personajes, también niega la de los espacios en los que habitan. Kinetta es un pueblo turístico situado en Ática-oeste, a 45 kilómetros de Atenas. En verano se llena de turistas ávidos de playa y sol, pero en invierno la localidad alberga menos de 2.000 habitantes. En invierno, por lo tanto, es un contenedor vacío, un contenedor sin contenido. El hotel donde trabaja la protagonista o la casa de otro de los personajes son muestra de ello $[7,8]$.

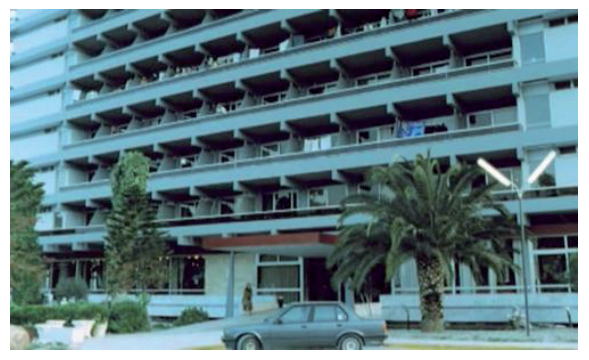

Figura 7. Hotel vacío

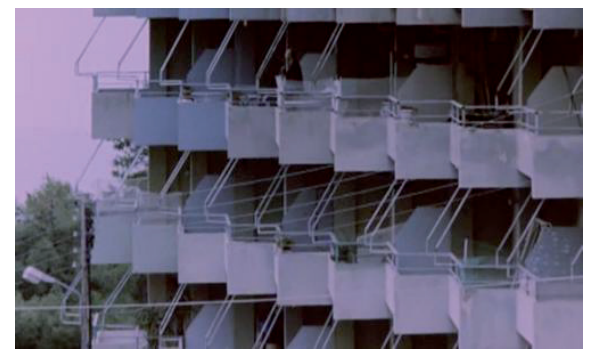

Figura 8. Casa vacía

Los edificios de Kinetta son edificios vacíos, que no dicen nada, copia de otros tantos edificios que hay en el mundo. En Dogtooth y Alps ocurre lo mismo. En una escena en la que Monte Rosa va a la playa, en Alps, el director muestra el espacio en un plano general en el que el elemento que más llama la atención es un gran poste de electricidad que hay en el centro. En la parte de abajo la carretera tiene mucha presencia y en la de arriba se pueden observar varios cables [9]. Monte Rosa camina hacia la playa y el director corta a un plano más corto. Pero también en ese plano llaman mucho la atención unos contenedores amarillos y otro tipo de suciedad que hay en la playa [10]. Cuando se muestran otros lugares la tendencia es la misma: son lugares feos donde hay grafitis, papeleras, coches, edificios viejos e insípidos... $[11,12]$. 


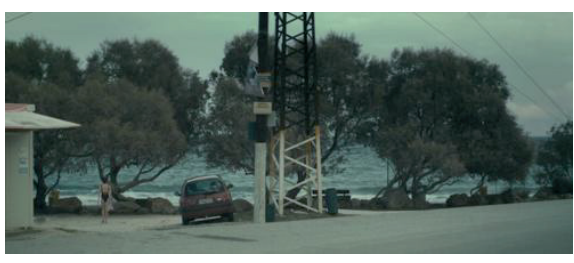

Figura 9. Poste de electricidad

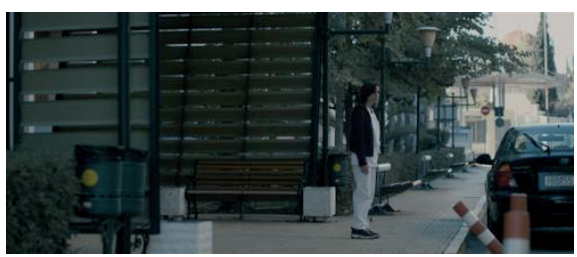

Figura 11. Papelera y coches

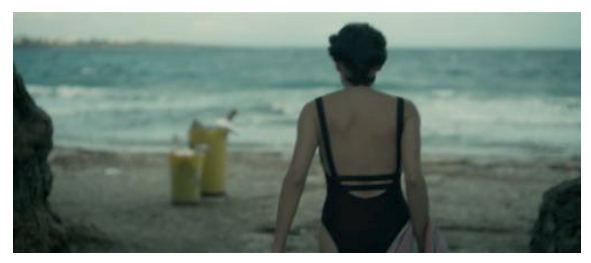

Figura 10. Contenedores amarillos

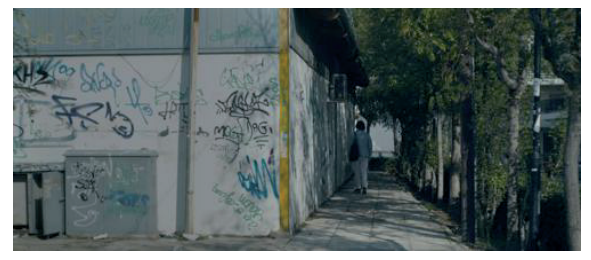

Figura 12. Grafitis

Acorde a los personajes que viven en ellos, los lugares también son lugares sin identidad. Son no-lugares, utilizando la famosa categoría de Marc Augé. Así explica el concepto del no-lugar Odeta Žukauskiené; primero aclara lo que son los lugares, para después definir lo que serían los no-lugares:

Place hold people with the same cultural background together, strengthen the sense of belonging to their country, history and culture. [...] To these places anthropologist opposes non-places - spaces that create neither identity nor relationships, neither shared cultural symbols nor monuments ${ }^{2}$. (Žukauskienè, 2016, p. 109)

Como podemos observar, los no-lugares son espacios que reflejan la falta de identidad del individuo posmoderno e invitan a reflexionar sobre la relación que existe entre las personas y los lugares en los que estos habitan.

\section{AMOR LÍQUIDO}

Según Guido Arditi, los trabajos industrializados que crea el capitalismo convierten al trabajador en una pieza más del proceso de producción (2018). Los trabajos modernos son labores mecánicas, no-creativas, en las que el trabajador debe realizar la misma función una y otra vez. En este sistema la personalidad del trabajador deja de tener valor y eso conlleva que todo trabajador sea fácilmente sustituible por otro. Este proceso despersonaliza al trabajador, que pierde una forma en la que podía definirse a sí mismo y en última instancia avanza en el proceso de pérdida de identidad del individuo. Arditi argumenta que como respuesta a esta pérdida de identidad nació el amor romántico:

Aquella identidad que es desdibujada en el ámbito del trabajo, les es restituida a los sujetos modernos a través de sus parejas; las cuales devienen parte integral de su identidad. Pues significan la existencia de un otro para el cual aquello que piensan, hacen, proponen o dicen es importante. $Y$, por lo tanto, es a través de este otro que adquieren un atestiguamiento de sí y dan sentido a sus vidas. (Arditi, 2018, p. 45)

\footnotetext{
${ }^{2}$ Los lugares mantienen a la gente de similar herencia cultural unida, refuerzan el sentido de pertenencia a su nación, su historia y su cultura. [...] Frente a estos lugares, los antropólogos oponen los no-lugares - espacios que no crean ni identidad ni relaciones, ni símbolos culturales compartidos ni monumentos.
} 
Por lo tanto, es a través de la pareja o la familia como el individuo moderno intenta dotar de significado a su existencia. No obstante, en la sociedad posmoderna el amor romántico también está desapareciendo y otro tipo de amor, un amor que podríamos denominar posmoderno, está cogiendo fuerza. Esto ocurre debido a que varias de las características de la sociedad capitalista y consumista posmoderna también se están extendiendo al ámbito del amor o de la pareja. Así, en las relaciones contemporáneas ya no se busca tanto la continuidad de la pareja, sino obtener satisfacción o placer inmediatos. Nos encontramos ante lo que Zygmunt Bauman denomina amor líquido (2005), donde la estabilidad del amor romántico se está liquidificando:

Las prácticas románticas nos orientan a comprometernos en el mantenimiento de relaciones profundas, a dejarnos llevar por la emoción, a sacrificarnos por el otro, considerando estas, características de real o verdadero amor. Por el contrario, las prácticas líquidas, abogan por relaciones libertarias, superficiales y hedónicas, abordadas de forma racional, siendo prácticas comunes en las relaciones virtuales. (Sánchez-Sicilia y Cubells, 2018, p. 168)

En la sociedad consumista posmoderna las relaciones de amor también han adquirido la relación de consumidor/producto. "Nada de enamorarse... Nada de esas súbitas mareas de emoción que lo dejan sin aliento" (Bauman, 2005, p. 38) escribe el sociólogo polaco-británico en Amor líquido. Las relaciones románticas se basaban en las emociones, pero el amor líquido es totalmente racional. Encontrar una cita en Tinder es un acto tan racional como ir al supermercado a comprar una botella de vino o unas galletas. Mencionamos Tinder porque la cuarta película de Lanthimos, The Lobster, muestra el choque de estos dos tipos de amor que acabamos de explicar -el romántico y el posmoderno o líquido- y para representar el posmoderno se hacen varias referencias a las aplicaciones para ligar.

The Lobster es una distopía donde cada individuo está obligado a tener pareja. Los individuos que se quedan solteros son ingresados en un hotel y ahí tienen 45 días para encontrar "el amor". De no hacerlo, serán convertidos en animales. El protagonista decide que si no consigue encontrar pareja quiere que le conviertan en una langosta, y de ahí viene el título de la película: The Lobster (La Langosta).

Muchos críticos han entendido la película como una crítica al modus operandi de las apps de citas (Cooper, 2016), puesto que se pueden encontrar muchas referencias a dichas aplicaciones a lo largo de la cinta. Por ejemplo, cuando el protagonista encuentra una posible candidata a ser su pareja, esta clama: "I think we're a match", lo cual es una clara referencia a la aplicación Tinder, que anuncia con esa frase cuando encuentra dos personas potencialmente compatibles.

Estas aplicaciones buscan semejanzas entre las posibles parejas y en The Lobster obligan a los personajes a actuar de la misma forma: "That obsession with matching characteristics seems like a satire of the questionnaire-based compatibility algorithms on dating sites like OKCupid ${ }^{3 \prime \prime}$ (Robinson, 2016). Lanthimos critica esta característica del amor posmoderno pues hace ver que buscar semejanzas en la posible pareja -lo que los expertos denominan "positive

\footnotetext{
3 Esa obsesión de encontrar características semejantes parece una sátira de los algoritmos de compatibilidad basados en cuestionarios que utilizan las aplicaciones de ligar como OKCupid.
} 
assortative mating" o emparejamiento selectivo- es un claro síntoma del comportamiento narcisista. Y, según Freud, el narcisismo es un sentimiento contrario al amor:

For Freud, "[a] person who loves has, so to speak, forfeited a part of his narcissism, and it can only be replaced by his being loved". Two are needed for love rather than selflove, but Narcissus dwells in The Lobster at the very heart of the twosome: what one looks for in the other is what one sees in oneself ${ }^{4}$. (Cooper, 2015, p. 166)

Aparte del narcisismo, la racionalidad del amor posmoderno también se critica con claridad en The Lobster. Y es que, como dicen Juan Orellana y Jorge Martínez en el libro Celuloide Posmoderno, "el narcisismo no puede sustraerse a su relación con el racionalismo moderno, del que es su máxima radicalización" (2010, p. 14). Así, Lanthimos subraya la falta de emociones en todos los aspectos de la sociedad, no solo en el amor. El director resalta este elemento utilizando colores desaturados con tintes cianes o azules, como se ve en los fotogramas $[13,14]$. Además, el cielo está siempre nublado, la luz artificial es mínima y la mayoría de planos son medios o generales, para evitar crear empatía con los personajes y llevar el relato a un terreno emocional.

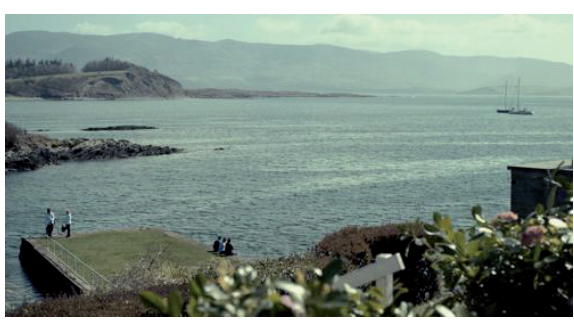

Figura 13. Colores cianes y desaturados

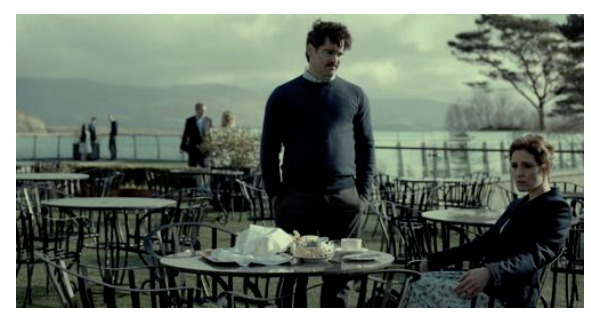

Figura 14. Colores cianes y desaturados

En The Lobster se muestra un amor racional, egoísta y narcisista. Lo mismo sucede en The Killing of a Sacred Deer (Lanthimos, 2017). En esta película un padre de familia, Steven, recibe una maldición por la cual deberá sacrificar a un miembro de su familia. La historia se basa en el mito griego de Ifigenia, en el que el rey Agamenón se ve obligado a matar a su hija por orden de la Diosa Artemisa.

Steven tarda mucho en aceptar que deberá sacrificar a uno de sus dos hijos o a su mujer, pero sus familiares asumen la situación con más premura y empiezan a convencer al padre para que mate a otro miembro de la familia en su lugar: "Creo que lo más lógico, por duro que pueda sonar, es matar a un niño" le dice la mujer, Anna, a Steven cuando están los dos en la cama. Los hijos también intentan convencer al padre para que no sea ellos los elegidos. Como se puede observar, más allá de una falta de amor, los personajes muestran gran falta de humanidad y empatía.

Algunos críticos han definido la situación sentimental de los personajes de The Killing of a Sacred Deer como "anestesia sentimental", haciendo alusión a la forma que tienen los padres de mantener relaciones sexuales: "Su vida rutinaria carente de emociones los congela tanto que, incluso cuando tienen relaciones sexuales, llevan a cabo juegos consistentes en fingir un

\footnotetext{
${ }^{4}$ Para Freud, una persona que ama, por decirlo así, debe haber renunciado a parte de su narcisismo, y solo puede ser reemplazado por su amor. Dos son necesarios para el amor, no como en el amor propio del narcisismo. Pero en La Langosta el narcisismo ocurre en el mismo corazón de las parejas: lo que uno busca en el otro es lo que ve en sí mismo.
} 
estado de anestesia. No fingen, están anestesiados" (Grijalva, 2018). Y es que al principio de la película se puede observar que para mantener relaciones sexuales la madre actúa como si estuviera bajo los efectos de una anestesia general [15].

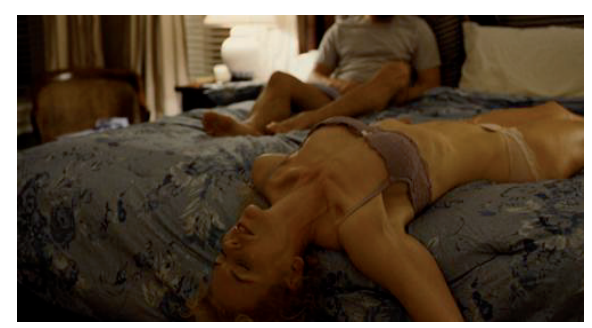

Figura 15. Anestesia general

\subsection{Sexo como herramienta}

El sexo en la sociedad posmoderna -y el sexo en el cine de Yorgos Lanthimos- es un acto que nada tiene que ver con el amor o los sentimientos. Las prácticas sexuales de los padres de The Killing of a Sacred Deer son reflejo de ello, pero un ejemplo más claro de lo que es el sexo se puede observar en otra escena en la que la madre desea obtener una información de manos de un amigo de su padre. "¿Qué obtendré yo a cambio?" le pregunta el hombre a Anna. La respuesta es clara: placer sexual.

En el cine de Lanthimos el sexo es una herramienta, una mercancía que puede intercambiarse por otra. Otro ejemplo claro lo vemos en The Favourite, donde la protagonista utiliza el sexo para ganarse el favor de otros personajes. También en Alps, donde Monte Rosa recurría al sexo para conseguir la atención de sus clientes.

En Dogtooth se muestran varias escenas de sexo, "which are disquieting precisely because of a lack of either passion or pathology ${ }^{5 \prime \prime}$ (Fisher, 2011, p. 22). En esta película se muestra una familia donde los tres hijos tienen prohibido abandonar la casa en la que viven. En consecuencia, el padre de la familia contrata a una mujer para satisfacer las necesidades sexuales de su hijo mayor.

En este caso el sexo es una herramienta para mantener al hijo bajo control, ya que, como aseguraba Freud, el instinto sexual de los subordinados debe ser controlado por el poder para evitar que los subordinados se subleven:

As proposed by Freud, sexual frustration and unsatisfied sexual urges can lead to violent behaviour. Aware of the possible destructive behaviour the son might adopt due to his unsatisfied sexual desires, which can be threatening for his authority and power over the family structure, the father guarantees that his son's sexual needs are satisfied in one way or another ${ }^{6}$. (Kizilay, 2020, p. 171)

\footnotetext{
${ }^{5}$ que son inquietantes precisamente por su falta de pasión o patología.

${ }^{6}$ Como decía Freud, la frustración sexual y los deseos sexuales no realizados pueden llevar a una conducta violenta. Consciente del posible comportamiento destructivo que su hijo podría tomar debido a sus deseos sexuales no resueltos, que podría ser peligroso para la autoridad y el poder de la estructura familiar, el padre se asegura de que las necesidades sexuales de su hijo sean satisfechas de una forma $u$ otra.
} 
Al igual que en las demás películas, por supuesto, el acto sexual en Dogtooth nada tiene que ver con las emociones. Es más, como dice Mario Psaras en el libro The Greek Weird Queer Wave, "sex is presented as being as mechanical as driving the car to the family's house" (2016, p. 67). El sexo es un elemento que está totalmente alienado en la sociedad posmoderna, donde incluso prácticas como el incesto son acometidas sin excesivos escrúpulos.

\section{INUTILIDAD DEL LENGUAJE}

El sexo en Dogtooth es una herramienta para mantener el poder, pero la herramienta principal, el recurso con el que los padres mantienen prisioneros a los hijos, es el lenguaje. En la primera escena de la película aparecen los tres hijos escuchando un radiocasete. La voz que sale de él -que es la voz de la madre- dice así: "Las nuevas palabras del día son: mar, autopista, excursión y carabina. Mar es la silla de piel con brazos de madera como la de la sala de estar. Ejemplo: no te quedes de pie, siéntate en el mar para que conversemos. Autopista es un viento muy fuerte. Excursión es..." así sigue la voz de la madre, explicando a los hijos lo que significan ciertas palabras.

La idea que mejor refleja el planteamiento de Lanthimos, en este sentido, es el del filósofo y lingüista austríaco Ludwig Wittgenstein, quien defendía que los límites de nuestro lenguaje suponen los límites de nuestro mundo. En este caso, como acabamos de explicar, los padres manipulan la percepción de la realidad de los hijos mediante la manipulación del lenguaje:

The film proved that we cannot fathom that which language does not cover. As man lives and fulfills his humanity, his language structures the resources of his knowledge. One knows about things when he can say something about them, and your utterance can exhaust the limits of what you know ${ }^{8}$. (Alfajora, 2011, p. 7)

Los hijos no pueden desear lo que no saben que existe. Por eso los padres cogen palabras que puedan darles información sobre el exterior y les dan un significado del interior de la casa.

Una idea parecida es la que se trata en la famosa novela de George Orwell 1984 (2013). En esta novela se presenta una sociedad totalitaria que controla estrictamente a sus ciudadanos y una de las herramientas para ejecutar ese control es la manipulación del lenguaje. En la novela, el Partido (el partido totalitario que ostenta el poder) ha creado un nuevo lenguaje llamado Newspeak (o lenguaje nuevo) que pretende sustituir el Oldspeak (o lenguaje viejo) para el año 2050. El principal objetivo del Newspeak es hacer el diccionario cada vez más fino mediante la eliminación de las palabras que puedan resultar peligrosas para el Partido. Así, por ejemplo, la palabra libertad es eliminada del nuevo diccionario. De esa forma, para los ciudadanos es mucho más difícil desear -y qué decir luchar por- la libertad política. Lo mismo ocurre con la palabra mentira. Eliminando las palabras que representan ciertas ideas del diccionario se convierte mucho más difícil el pensar o el hablar sobre esas ideas.

Deleuze y Guattari lo tienen claro: "el lenguaje ni siquiera está hecho para que se crea en él, sino para obedecer y hacer que se obedezca" (1994, p. 81). El lingüista Norman Fairclough

\footnotetext{
7 el sexo es presentado como una acción tan mecánica como conducir el coche familiar a la casa.

${ }^{8}$ La película demuestra que no podemos comprender lo que el lenguaje no abarca. Cuando las personas van viviendo y consumando su humanidad, su lengua estructura los recursos de su conocimiento. Alguien solo sabe algo cuando puede decir algo sobre ello, y tu expresión puede agotar los límites de lo que sabes.
} 
también hablaba sobre el poder del lenguaje en la misma dirección, cuando afirmaba que el lenguaje permite a unas personas dominar a otras, pues la conciencia es el primer paso hacia la soberanía (1989).

Al principio de Dogtooth, después de que los hijos hayan escuchado las nuevas palabras del día, la hija menor propone un juego: meter un dedo en agua caliente para ver quién de los tres es el que más aguanta sin sacarlo. A la hermana mayor y al hijo les parece bien, y empiezan a discutir sobre las normas del nuevo pasatiempo. Después, la hermana mayor pregunta cómo se llama el juego. Nadie lo sabe. Se crea un silencio, y acto seguido, la escena termina. El juego se queda sin ser realizado. Aquí se ve que Lanthimos defiende que lo que no puede ser nombrado no existe. Este elemento hace pensar en los personajes, que como hemos dicho antes no tienen nombre. $Y$ también en las palabras manipuladas que aprenden los hijos, como mar o excursión. Las cosas y las personas, para existir, necesitan un nombre que afirmen su existencia.

Lanthimos subraya la inutilidad de las palabras para transmitir un mensaje o un sentimiento. El lenguaje sirve para manipular, para dar ordenes, para establecer jerarquías... pero no para relacionar de verdad a las personas. "En la era de la información se generalizan paradójicamente los problemas de comunicación y las malinterpretaciones", asegura Raúl Martínez en su tesis doctoral Jim Jarmusch desde la posmodernidad (2014, p. 26). Por eso los personajes de todas las películas de Lanthimos están solos, aislados, sin poder comunicarse o crear relaciones afectivas con el resto de seres humanos.

\section{AISLAMIENTO FORZADO}

Como consecuencia del fracaso del lenguaje, los personajes del autor griego viven aislados y en soledad. "Se han ido rompiendo los vínculos de dependencia vertebradora en el lapso de los últimos siglos" escriben Orellana y Martínez; "primero con Dios, después con la naturaleza, por último, con los otros" (2010, p. 40). Así ha evolucionado la sociedad en los últimos años: desde la pérdida de importancia de la religión hasta llegar a la sociedad líquida actual, compuesta por individuos digitalmente conectados, pero emocionalmente aislados o anestesiados.

El ejemplo más claro de este aislamiento puede ser observado en The Favourite, donde para reflejar esa característica el director coloca a los personajes en un palacio inmenso: "From the beginning, I had this image of these lonely characters in huge spaces" (Smith, 2018) declara Lanthimos en una entrevista. El director utiliza en esta película planos de gran angular y de ojo de pez (con objetivos de hasta $6 \mathrm{~mm}$ ) en los que los personajes se ven muy pequeños, insignificantes y perdidos [16,17]. Además, da la sensación de que los personajes están atrapados y crea una sensación claustrofóbica, como explica el director de fotografía de la película Robbie Ryan:

If you read between the lines what the lenses did for the film, the thing I [took from] watching the film was it felt very claustrophobic. By the nature of being able to see everything in front of you, you then get a sense that the characters are almost

\footnotetext{
${ }^{9}$ Desde el principio me imaginé estos personajes solitarios en espacios inmensos.
} 
imprisoned in the location. Even though they have all this luxury and power, they are a little bit isolated in this world ${ }^{10}$. (Grobar, 2018)

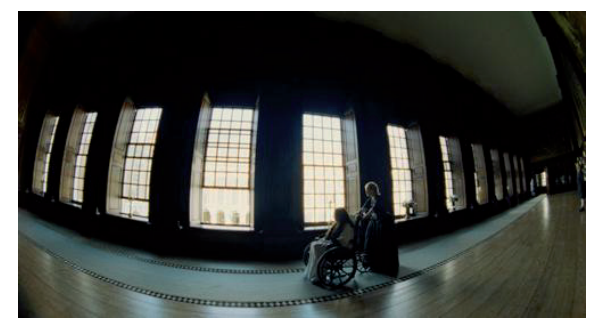

Figura 16. Gran angular

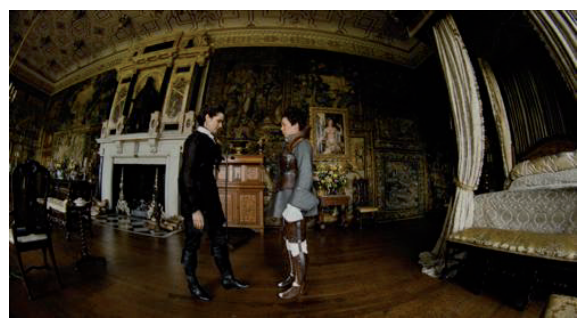

Figura 17. Gran angular

El director utiliza los espacios de forma tal que crean una sensación de encarcelamiento. Aparte de The Favourite, este elemento se hace evidente tanto en Dogtooth como en The Lobster, donde los personajes viven literalmente encarcelados ya sea en la casa o en el hotel, pero también en el resto de películas. En Kinetta, por ejemplo, para representar esta característica se muestra a los personajes solos en espacios inmensos [18] o atrapados en sus casas y lugares de trabajo [19].

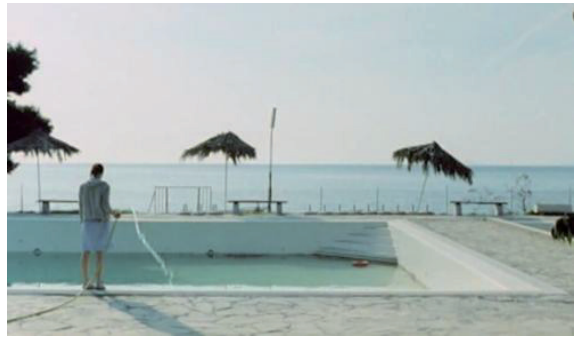

Figura 18. Personajes encarcelados

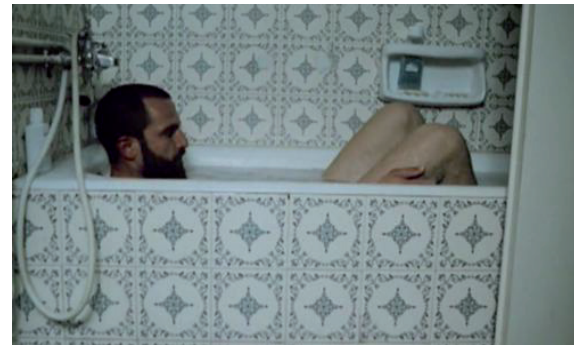

Figura 19. Personajes encarcelados

Por otro lado, en The Killing of a Sacred Deer llama la atención que a menudo se muestra a los personajes atrapados en espacios cerrados con ventanas rayadas que se asemejan a los barrotes de una cárcel [20]. Lo mismo sucede en The Favourite [21] donde, además, el palacio real se dibuja como si fuera un verdadero laberinto gigantesco (con pasadizos secretos y corredores infinitos) del que los personajes no saben cómo salir. Además de eso, los personajes se comparan con los conejos que la reina guarda en una jaula. Los animales están presos, igual que los protagonistas, aislados tras jaulas con barrotes, en una metáfora que se refuerza visualmente mediante los colores blancos y negros con los que se dibujan ambos elementos $[22,23]$.

\footnotetext{
${ }^{10} \mathrm{Si}$ lees entre líneas lo que los objetivos aportan a la película, lo que yo sentí al ver el filme es un sentimiento de claustrofobia. Teniendo la habilidad de ver todo lo que ocurre enfrente tuyo sientes que los personajes están prisioneros en el espacio. A pesar de tener todo ese lujo y poder, están un poco aislados en el mundo.
} 


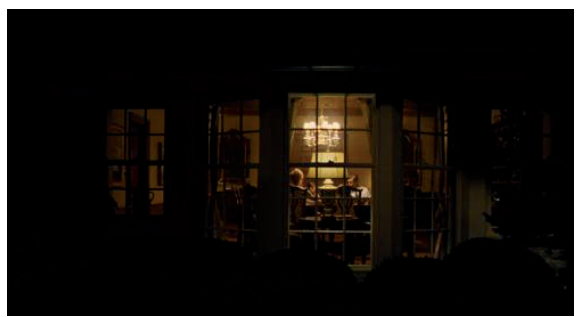

Figura 20. Ventanas con barrotes

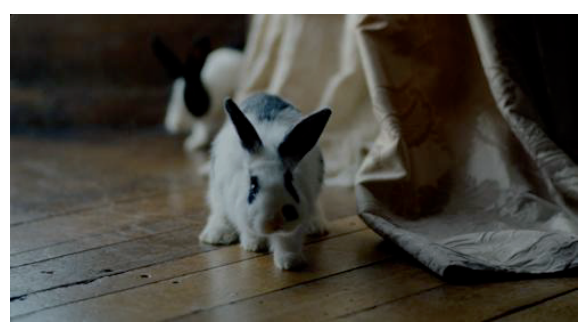

Figura 22. Conejos blancos y negros

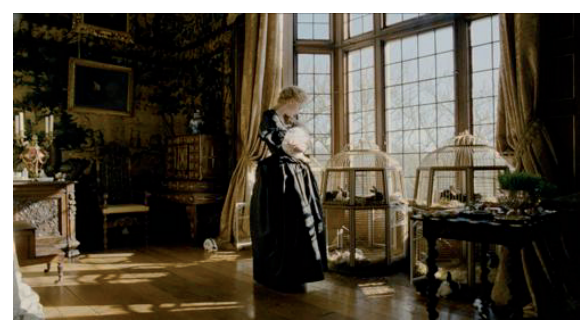

Figura 21. Ventanas con barrotes

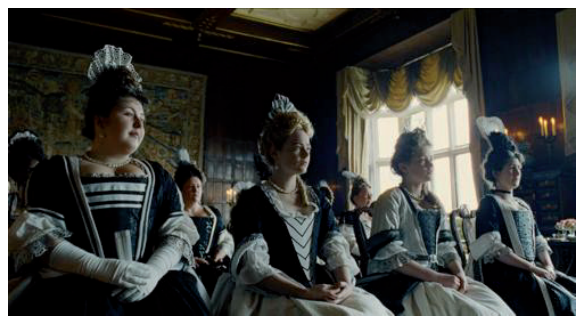

Figura 23. Personajes blancos y negros

El individuo posmoderno es un ser que vive encarcelado y aislado del resto de sus coespecímenes. Vive marginado, excluido de la socialización, solo. Según Gérard Imbert esta forma de aislamiento es típicamente neoexistencialista. El autor argumenta que el individuo posmoderno no se siente parte del sistema, pero tampoco se levanta contra él. El individuo posmoderno se enfrenta al sistema de una forma blanda, "en una forma de resistencia pasiva típicamente posmoderna" (2019, p. 158). Reflejo de la sociedad líquida contemporánea donde nada es para siempre - $y$, por lo tanto, nada es importante- el individuo posmoderno es un ser pasivo, sin motivación, al que le cuesta relacionarse y encontrar su lugar en la sociedad. En contraste a los personajes del cine clásico, el personaje posmoderno se limita a sobrevivir:

Hay un modo posmoderno de vivir en los bordes, al margen de la sociedad, sin ser obligatoriamente un marginado social. Corresponde a un estado liminar, un vivir sin estar del todo integrado [...]. Se traduce obviamente por una relación distanciada con el entorno humano, con el tiempo, el vivir en el presente más inmediato y en la falta de perspectivas de futuro. (Imbert, 2019, p. 169)

Vivir en los bordes, en los márgenes, dice Imbert. Así es precisamente como se muestra a los personajes de Alps, por ejemplo, quienes no tienen la suficiente importancia, no son lo suficientemente significantes para ocupar el centro del plano [1,2]. Son personajes sin identidad, alejados los unos de los otros, incapaces de relacionarse y comunicarse entre ellos.

\section{CONCLUSIONES}

Yorgos Lanthimos retrata una sociedad que ha perdido el norte por perseguir el sueño capitalista, que ha olvidado sus raíces, su historia, su identidad. Los lugares han perdido su esencia y lo mismo ha ocurrido con los seres humanos que viven en ellos, quienes han sufrido un fuerte proceso de alienación.

Las características que conforman el sistema consumista contemporáneo han terminado por contagiar la esfera privada y el amor se ha convertido en un bien consumible, un placer inmediato y desechable. El sexo se ha convertido en una mercancía.

El lenguaje ha mostrado su inutilidad a la hora de crear lazos afectivos entre personas y de dar 
sentido a la realidad y se ha convertido en una herramienta con la que los poderosos mantienen a sus súbditos bajo control. Como consecuencia, los individuos no consiguen conectar entre ellos y a falta de un objetivo común se encuentran aislados y solos.

Este es el retrato que hace el cineasta Yorgos Lanthimos del individuo posmoderno. A todas estas características habría que sumarle, además, la constante amenaza de violencia bajo la que viven los personajes, y también la estricta jerarquía con la que se organiza la sociedad. Esto no significa que los citados elementos sean las principales características de la sociedad posmoderna, sino que son las que este concreto cineasta destaca en sus personajes. Así, se deja abierta la posibilidad de seguir investigando tanto estos aspectos como los retratos que otros directores realizan del individuo y la sociedad posmodernas.

El cine de Lanthimos es un cine que a primera vista puede parecer absurdo o incluso ridículo, pero observar a sus personajes con detenimiento basta para que el espectador se de cuenta de que bajo las premisas disparatadas del director se esconden retratos precisos de la sociedad contemporánea; de lo que es hoy en día y de lo que podría ser en un futuro si no se cambian las cosas.

\section{Referencias}

Alfajora, J. C. (2011). On Language and Morality. Rethinking the Role of Language in the Formation of Moral Values through analysis of Lanthimos' Dogtooth. https://tinyurl.com/aw3vhvec

Almodóvar, P. (Director). 2011. La Piel que habito [película]. El Deseo P. C., Blue Haze Entertainment, Canal+ España, Televisión Española, Instituto de la Cinematografía y de las Artes Audiovisuales, FilmNation Entertainment.

Arditi, G. (2018). Amor y Capitalismo. Revista Ariel, 22, 41-50. https://tinyurl.com/57jtwun8

Bauman, Z. (2003). Modernidad líquida. Fondo de Cultura Económica.

(2005). Amor líquido. Acerca de la fragilidad de los vínculos humanos. Fondo de Cultura Económica.

Betancur, M. C. (2010). Persona y Máscara. Praxis Filosófica, 30, 127-143. https://doi.org/10.25100/pfilosofica.v0i30.3419

Bordwell, D. (1996). La Narración en el Cine de Ficción. Paidós.

Cooper, S. (2016). Narcissus and The Lobster. Studies in European Cinema, 13(2). https://doi.org/10.1080/17411548.2016.1216373

D’angelo, V. (2016). La máscara que luego estoy siguiendo. Sobre la relación entre cuerpo y sujeto en la obra de Erving Goffman. Daimon: Revista Internacional de Filosofía, 5, 389-398. https://doi.org/10.6018/daimon/268931

Deleuze, G. y Guattari, F. (1994). Mil mesetas: Capitalismo y esquizofrenia. Pre-textos.

Eagleton, T. (1997). Las ilusiones del posmodernismo. Paidós.

Fairclough, N. (1989). Language and Power. Longman.

Goffman, E. (1997). La presentación de la persona en la vida cotidiana. Amorrortu.

Grobar, M. (2018). The Favourite DP Robbie Ryan Brings Fisheye Lenses \& Fluid, Roving Camera To Yorgos Lanthimos' Madcap Period Piece. Deadline. https://tinyurl.com/4yab7hek

Fisher, M. (2011). Dogtooth: The Family Syndrome. Film Quarterly, 64(4), 22-27. https://doi.org/10.1525/fq.2011.64.4.22 
Grijalva, A. (2018). The Killing of a Sacred Deer: la sublimación estética de una nueva tragedia. Cine Oculto. https://tinyurl.com/4tzvvu5a

Imbert, G. (2019). Crisis de valores en el cine posmoderno. Cátedra.

Kizilay, Y. (2020). Dogtooth: Entrapment in a perceptual prison. Ankara Üniversitesi Sosyal Bilimler Dergisi, 11(1), 167-173. https://tinyurl.com/4rr6wb2s

Lanthimos, Y. (Director). 2005. Kinetta [película]. Haos Films, Modiano Inc, Top Cut, STEFI Cine \& TV Productions, Kino.

Lanthimos, Y. (Director). 2009. Dogtooth [película]. Boo Productions.

Lanthimos, Y. (Director). 2011. Alps [película]. Haos Films.

Lanthimos, Y. (Director). 2015. The Lobster. [película]. Element Pictures, Scarlet Films, Faliro House, Haut et Court, Lemming Films, Film4 Productions.

Lanthimos, Y. (Director). 2017. The Killing of a Sacred Deer [película]. Element Pictures, A24, Film4.

Lanthimos, Y. (Director). 2018. The Favourite [película]. Element Pictures, Scarlet Films, Film4 Productions, Waypoint Entertainment.

Lanthimos, Y. (Director). 2019. Nimic [cortometraje]. Superprime.

Lasagna, R. y Pallavidino, B. (2019). Anestesia di solitudini: Il cinema di Yorgos Lanthimos. Mimesis Edizioni.

Martínez, R. (2014). Jim Jarmusch desde la posmodernidad. [Tesis Doctoral, Universitat Ramon Llull]. Repositorio Universitat Ramon Llull. FCCB - Comunicació. http://hdl.handle.net/10803/298176

Muñoz, H. (2015). Posnarrativo: el cine más allá de la narración. [Tesis Doctoral, Universidad de Salamanca]. Repositorio Documental Gredos. http://hdl.handle.net/10366/128242

Navarrete-Cazales, Z. (2015). ¿Otra vez la identidad? Un concepto necesario pero imposible. Revista Mexicana de Investigación Educativa, 20(65), 461-479. https://tinyurl.com/8srftc5v

Orellana, J. y Martínez, J. (2010). Celuloide Posmoderno: Narcisismo y autenticidad en el cine actual. Ediciones Encuentro.

Orwell, G. (2013). 1984. Editorial DeBolsillo.

Papanikolaou, D. (2020). Greek Weird Wave: a cinema of biopolitics. Edinburgh University Press.

Psaras, M. (2016). The Queer Greek Weird Wave: Ethics, Politics and the Crisis of Meaning. Palgrave Macmillan.

Robinson, T. (2016). The Lobster draws out an illogical world to its most logical ends. The Verge. https://tinyurl.com/rmdmjjdc

Sánchez-Sicilia, A. y Cubells, J. (2018). Amor, posmodernidad y perspectiva de género: entre el amor romántico y el amor líquido. Investigaciones feministas, 9(1), 151-171. https://doi.org/10.5209/INFE.58143

Smith, S. (2018). Yorgos Lanthimos's Venice Film Festival crowd pleaser The Favourite filmed almost exclusively at Hatfield House, Hertfordshire. The Location Guide. https://tinyurl.com/kztnhcra

Zukauskienė, O. (2016). A philosophical topography of place and non-place: lithuanian context. Coactivity: Philosophy, Communication, 24(2), 108-118. https://doi.org/10.3846/cpc.2016.244

\section{Semblanza del autor}

Mikel Peña Sarrionandia es licenciado en Comunicación Audiovisual en la Universidad del País Vasco y tiene un máster en Edición y post-producción de vídeo. Desde el 2013 trabaja en la productora de vídeo Zirriborro, donde realiza las funciones de editor, cámara, post-productor y 
colorista. Entre sus trabajos destacan el cortometraje Aurrera, estrenada en el Bilbao Mendi Film Festival, el documental Arriesgarse a Vivir o el programa de televisión El Lector de Huesos, ganador del Premio Especial en el FesTVal de 2016 y del Premio Pello Sarasola al Mejor Programa Autonómico en el mismo año. 